\title{
Cabo Verde: democracia, cultura política e esfera pública*
}

\section{Cape Verde: democracy, political culture and the public sphere}

Nataniel Andrade Monteiro'

Recebido em: 16/10/2015. Aprovado em: 03/03/2016.

1 Investigador no Centro de Investigação em Desenvolvimento Local e Ordenamento do Território (CIDLOT- Uni-CV). Licenciado em Ciência Política e Mestre em Ética e Filosofia Política pela Universidade de Cabo Verde (Uni-CV). E-mail: natanmonteiro88@hotmail.com.

\section{Resumo}

$\mathrm{O}$ artigo procura contribuir para se compreender e descrever aquilo que, no meu entender, constitui a nova abordagem da discussão acerca da cultura política e da esfera pública em Cabo Verde. A pobreza, o desemprego, a justiça social e a segurança, entre outros assuntos, têm sido alvos de atenção por parte da sociedade civil cabo-verdiana, sobretudo a partir da década de noventa, com o advento da democracia. O que me incita a pensar sobre novas tendências no que se refere à cultura política dos cabo-verdianos, particularmente na afirmação e configuração de uma esfera pública que prima pela prática do debate e respeito pela opinião pública, capaz de influenciar as acções do sistema político. O ano de 2015 tem sido marcado por debates de repercussão nacional e internacional, como é o caso mediático do Estatuto de Titulares de Cargos Políticos (ETCP). Este acontecimento, ao que tudo indica, possibilita uma nova configuração da esfera pública cabo-verdiana, corroborada numa cultura política participativa, de modo que sirva, não apenas para os períodos eleitorais, mas igualmente como instrumento para a consolidação do sistema político.

Palavras-chave: Cabo Verde. Democracia. Cultura política. Esfera pública.

\section{Abstract}

The article aims to understand and describe what, in my view, is the new approach of the discussion about the political culture and the public sphere in Cape Verde. Poverty, unemployment, social justice and security, among other issues, have been targets of attention by the Cape Verdean civil society, especially from the early 1990s with the advent of democracy. What encourages me to think about new trends concerning to political culture of Cape Verdeans, particularly on the statement and configuration of a public sphere for the practice of debate and respect for public opinion, able to influence the actions of the political system. The year 2015 has been marked by debates of national and international repercussion, such as newsworthy the Status of Holders of Political Office (ETCP). This event, through all indications, enables a new reconfiguration of Cape Verdean public sphere, supported a participatory political culture, which serves not only to election periods, but also as an instrument for the consolidation of the political system.

Keywords: Cape Verde. Democracy. Political culture. Public sphere. 


\section{Introdução}

$\mathrm{O}$ arquipélago de Cabo Verde, descoberto em 1460/62 viveu, durante quase cinco séculos, sob o antigo regime colonial português, onde a estruturação do campo social e político, obedecia ao modelo proferido pelo regime. A esfera pública em Cabo Verde é, desde o regime colonial, restrita, havendo aqueles a que podemos descrever e caracterizar como líderes de opiniões ou mediadores de informações, recorrendo à teoria de Two-step-flow of communication. Estes líderes são pessoas que, por meio dos instrumentos de comunicação, neste caso a literatura, emitem opiniões sobre diferentes temas que se referem a valores culturais e identitários, a amplas parcelas da população ou a grupos específicos. Entre estes líderes encontram-se os jornalistas, intelectuais e professores (BOURDIEU, 1980).

Abordo neste contexto a geração de intelectuais Nativistas e Claridosos. A primeira geração servia-se de uma literatura que começou a tomar forma a partir do ano de 1800, quando "surgem os suportes capazes de possibilitar o desenvolvimento de uma literatura erudita" (FRANÇA, 1998, p.116). Destes suportes destaca-se, na década de quarenta do século XIX, o aparecimento do primeiro periódico, que, de uma forma mais abrangente, marcaria a imprensa em África, conhecido como o Boletim Oficial do Governo Geral de Cabo Verde, que além, de divulgar assuntos administrativos do Governo, também difundia anúncios e textos literários que punham em realce as manifestações, ainda que de forma tímida, dos anseios e do quotidiano do povo cabo-verdiano (OLIVEIRA, 1998). Mais tarde, surge na década de trinta do século passado a geração de intelectuais conhecida como Claridosos, nome dado em função da Revista Claridade, fundada na Ilha de São Vicente no ano de 1936. A revista era, de facto, o órgão de cultura e não meramente uma revista de letras, pois "de um lado, anotações sobre o comportamento do homem crioulo, ensaios de índole diversa; por outro lado, poemas, contos, peças de natureza literária e artística" (FERREIRA, 1973, p. 260).

Com a independência nacional em 1975 e o culminar da primeira República, o arquipélago deu os primeiros passos para uma nova estruturação do campo político, económico, social, cultural e literário. Sob influência de regimes socialistas um pouco por toda a parte, particularmente no contexto africano, o regime político cabo-verdiano acabou por se estruturar em tor- no do regime de partido único, caracterizado, segundo a Constituição da República, como Democracia Nacional Revolucionária. Neste regime, sob a liderança de um único partido político, Partido Africano da Independência da Guiné e Cabo Verde / Cabo Verde (PAIGC/CV), consagrado como a única força dirigente da sociedade civil e do Estado, não se verificava uma participação cívica que permitisse a estruturação adequada e consolidada da esfera pública em Cabo Verde. A geração desta época considerada como a geração dos anos 50 representava até certo ponto a esfera pública. Geração de índole nacionalista e portadora de ideais independentistas, tinha como objectivo e slogan a construção de uma nova terra e a ideia de Cabo Verde vinculado à África. Esta geração também serviu de suporte literário para fazer grande parte das suas intervenções. Considera-se ainda que neste contexto a proposição mais credível é que a cultura política era uma cultura de sujeição, característica dos regimes autoritários. Porém, a abertura política (1990) permitiu repensar os instrumentos da democracia nos moldes liberais e representativos com novos seguimentos no que se refere a participação cívico-política dos cabo-verdianos, ainda que de forma incipiente. Actualmente, os movimentos cívicos encontram-se organizados um pouco por todas as ilhas. Chamam a atenção para a análise da cultura política e das suas repercussões na esfera pública, actuando por exemplo sob a forma de lobbying e advocacy, utilizando para o efeito meios de comunicação mediáticos, como a televisão, a rádio, a imprensa e o ciberespaço, tentando romper com uma certa herança colonial.

Creio que existe uma necessidade urgente em analisar e interpretar para posteriormente explicar e compreender a configuração da esfera publica e da cultura politica no contexto da democracia caboverdiana, numa conjuntura nacional abalada por fenômenos sociais e políticos contundentes. Da iminência com a questão da originalidade em tratar a problemática da democracia, cultura politica e esfera publica em Cabo Verde, considero que o presente artigo constitui um valor acrescentado para este campo de estudo. Num contexto onde se verifica uma fraca doutrina de produção cientifica e, por conseguinte a necessidade urgente de se aprofundar acerca da democracia cabo-verdiana, onde é preciso analisar um conjunto de aspectos sociais e políticos que moldam este campo de estudo. Deste modo, procuro, através do método qualitativo, - nomeadamente na análise hermenêutica e na revisão da bibliografia - compreender este processo, 
particularmente o que se entende por uma nova abordagem da esfera pública em Cabo Verde, o que de facto está intrinsecamente ligada à cultura política e ao sistema político e económico deste arquipélago.

\section{Referencial Teórico}

\subsection{Cultura política e democracia liberal represen- tativa}

A democracia liberal representativa é, no contexto dos regimes políticos, considerada o regime que melhor se adequa às novas exigências do Estado de Direito, que prima, sobretudo, pela separação de poderes, liberdade de opiniões e o pluralismo político e ideológico. Nesta perspectiva, Rawls (1997), considera que este último elemento constitui um dos pilares fundamentais da democracia liberal representativa. Todos os antigos e actuais Estados autoritários do mundo "são ao mesmo tempo antiliberais e antidemocráticos" (BOBBIO, 2000, p. 44). A democracia e o liberalismo articularam-se no contexto das revoluções liberais, essencialmente na Revolução Americana (1776) e Revolução Francesa (1789), onde havia a necessidade da democracia proteger os direitos de liberdade, mas também por partilharem um ponto comum que é o individuo. Na óptica de Bobbio (2000, p. 44):

\begin{abstract}
Ideias liberais e o método democrático vieram gradualmente se combinando num modo tal que, se é verdade que os direitos de liberdade forma desde o início a condição necessária para a directa aplicação das regras do jogo democrático, é igualmente verdadeiro que, em seguida, o desenvolvimento da democracia se tornou o principal instrumento para a defesa dos direitos de liberdade.
\end{abstract}

A protecção, tanto da propriedade privada, como da igualdade de oportunidades, liberdade e paz só será possível num Estado democrático. Aliás, para o liberal, o Estado democrático constitui uma necessidade absoluta, uma vez que lhe cabem as mais importantes tarefas, nomeadamente, a protecção, não apenas da propriedade privada, mas também da paz, pois, em sua ausência, os benefícios da propriedade privada podem não ser recolhidos. Porém, o mais importante não é apenas proteger a propriedade privada, mas, acima de tudo, que este Estado seja capaz, a partir da sua estruturação, desenvolver-se de forma pacifica e voluptuosa de modo a que este desenvolvimento não seja interrompido por guerras civis e revoluções (VON MISES, 2010).

Actualmente a democracia liberal é a forma de go- verno mais difundida no mundo, e caracteriza-se pelo seu formato representativo, que se baseia fundamentalmente, no sufrágio universal, em que a independência dos membros eleitos está, inevitavelmente, vinculada às regras do Estado de Direito. Tendo como referencia um conjunto de direitos, na maioria das democracias liberais, destacam-se a "liberdade de expressão, associação e culto; devido processo legal; a propriedade e a igualdade perante a lei" (PEREIRA; CARVALHO, 2008, p. 49). A democracia liberal representativa caracteriza-se pelo pluralismo político em que a cultura política é "sempre marcada por uma diversidade de doutrinas políticas, religiosas, filosóficas e morais, opostas e irreconciliáveis" (RAWLS, 1997, p. 33). A cultura política constitui um dos pilares fundamentais para o sucesso ou fracasso de uma democracia. O termo refere-se a um conjunto de atitudes e orientações que se direccionam especificamente a objectos políticos, essencialmente, ao sistema político de forma geral e específico (ALMOND; VERBA, 1963). Cultura política é o "conjunto de actividades, normas, crenças, mais ou menos largamente partilhados pelos membros de uma determinada unidade social e tendo como objecto fenómenos políticos" (BOBBIO, 2000, p. 306).

De uma forma mais específica, a cultura política pode ser definida como um conjunto de tendências dos cidadãos de uma sociedade em relação à política (ALMOND; VERBA, 1963). Para estes autores é possível categorizar a cultura política em três tipos diferentes: primeiro a cultura política paroquial (Parochial Political Culture), que é característico das sociedades simples, como por exemplo as sociedades tribais africanas onde os papéis e as instituições de cunho especificamente político não existem ou coincidem com os papéis e as estruturas de carácter económico e religioso, ou seja, para os membros dessas sociedades as orientações políticas e as suas regras subjacentes estão intrinsecamente relacionadas com as suas orientações religiosas e sociais. Segundo, é a cultura política de sujeição (The Subject Political Culture), onde normalmente os membros da sociedade estão voltados essencialmente para o sistema político numa relação de passividade. Esta cultura corresponde principalmente aos regimes políticos autoritários. Por último, a cultura política de participação (The Participant Political Culture), que é contrária ao segundo tipo de cultura política, em que os cidadãos têm uma posição política mais activa, ou seja, os membros da sociedade tendem a ser explicitamente orientados para o sistema como um todo e para 
ambas as estruturas e processos políticos e administrativos impostos, tanto para a aspectos de entrada e como de saída do sistema político. Eles tendem a ser orientados para um papel activo na política, embora os seus sentimentos e avaliações possam variar da aceitação à rejeição (ALMOND; VERBA, 1963). Contudo, a cultura política pode variar de acordo com a realidade social e política de cada país ou Nação. Significa que a cultura política de uma determinada realidade pode combinar as diferentes tipologias acima referenciadas. Porque, reforçando a perspectiva de Rowls, a cultura política é "constituída por um conjunto de subculturas, isto é, por um conjunto de atitudes, normas e valores diversos, amiúde em contraste entre si” (BOBBIO, 2000, p. 307). Mas é precisamente a tensão entre estes valores que atravessam o campo cultural, que permitem cimentar o campo da esfera pública, como espaço de partilha de opiniões que se estruturam pela prática do debate e da representação. A construção de uma cultura política, sobretudo, marcada pela prática do debate, da representação, da elaboração de leis, entre outras, constitui um sustentáculo para a criação de uma esfera pública civil (BARATA, 2006).

\subsection{Esfera pública, democracia e novas tecnologias de informação e comunicação}

Os investigadores que se centram no estudo sobre a democracia, têm vindo, nas últimas décadas, influenciados pelo contexto contemporâneo, a aprofundar as relações entre esta e a esfera pública. Esta abordagem tem como referência a prática comunicativa como fonte geradora da opinião pública, capaz de influenciar as acções do sistema político democrático. No contexto da busca da consolidação das instituições democráticas, nomeadamente, no que se refere a eleições livres, o parlamento activo que cumpre na íntegra as suas funções, principalmente a função pedagógica, a liberdade de expressão, com particular atenção para a liberdade de imprensa, entre outros, chama a atenção para a incorporação de valores democráticos nas práticas quotidianas (AVRITZER, 1996).

A incorporação destes valores, além de permanecer ligada à esfera institucional, deve, acima de tudo, penetrar nas relações e processos sociais e na cultura política. Nexte contexto, revela-se necessário a interacção entre o Estado, as instituições políticas e a sociedade civil, num movimento de construção da democracia, que se apresenta como um processo importante na concretiza- ção da soberania popular e da esfera pública. Este último, no contexto democrático, é caracterizado como o campo imprescindível de constituição democrática da opinião e da vontade colectiva, a mediação necessária entre a sociedade civil, de um lado, e o Estado e o sistema político, de outro (HABERMAS, 2003). A esfera pública é uma das características centrais das sociedades modernas, formada a partir das mudanças oriundas do surgimento de nova sociedade burguesa e do Estado de Direito no século XVIII, em que Habermas (2003, p. 85) denominou inicialmente de esfera pública burguesa, e entendeu-a como o fio divisório entre o Estado e a sociedade. Esta intermediação é feita através da opinião pública que se "constitui em discussões públicas, depois do que o público, por formação e informação, se torna apto a formular uma opinião fundamentada."

Uma outra concepção sobre a esfera pública é apontada por Hannah Arendt na sua obra A Condição Humana (1958), que é muito influenciada pelo contexto do regime nazi da Alemanha na década 40 do século XX. A autora nesta obra analisa detalhadamente a noção da esfera pública como o lugar por excelência, onde o homem alcança a liberdade de participar por meio da palavra e da acção. Arendt (2007 [1958]). Ao analisar a condição humana, considera que existem três esferas da vita activa: o labor, o trabalho e a acção. Esta ultima, ou seja, a acção, constitui o elemento estruturante do conceito de esfera pública, e é a actividade comunicacional por excelência ligada à vida política, cuja preocupação fundamental se pauta pela busca de uma linguagem da pluralidade de opiniões e o bem comum.

A comunicação está no centro do conceito de esfera pública proposto por Arendt, na medida em que os actores se comunicam tendo em vista a obtenção de um acordo que beneficie a todos, daí resultando a construção de condições de autoridade. Na verdade não se deve esquecer que a liberdade, a comunicação e o agir conjunto podem ser elementos geradores do poder e são o "grande tema unificador da reflexão de Hannah Arendt" (LAFER, 2003, p. 35).

No que se refere à importância da comunicação na esfera pública ou espaço público, ela vem sofrendo significativas modificações desde a antiguidade, o que tem dado uma outra dimensão a este conceito. Actualmente verifica-se que, por causa da expansão das novas Tecnologias de Informação e Comunicação (TICs), a esfera pública ganha uma outra abordagem, tornando-se mais 
abrangente e inclusiva. Neste quadro, Habermas (1997) procurou dar uma outra tónica ao conceito de esfera pública, tendo no centro a questão da rede (interacção) que abriga a discussão de interesses colectivos. Para o autor a esfera pública pode ser caracterizada como uma rede apropriada para a comunicação de conteúdos, tomadas de posição e opiniões; nela os fluxos comunicacionais são filtrados e sintetizados, a ponto de se condensarem em opiniões públicas enfeixadas em temas específicos. A esfera pública é um espaço comum em que, supostamente, "os membros da sociedade se encontram através de uma variedade de meios - imprensa, electrónica e também encontros face a face - para discutirem assuntos de interesse comum e, deste modo, serem capazes de formar a seu respeito uma mente comum" (TAYLOR, 2010, p. 4).

O surgimento das TICs, essencialmente a internet, revolucionou o campo da esfera pública, na medida em que a comunicação se tornou mais acessível e mais abrangente. É um facto que os governos têm actualmente a possibilidade de entender melhor as necessidades dos seus cidadãos, os quais, por sua vez, poderão também participar melhor na decisão do seu governo através de vários instrumentos disponíveis no sistema político democrático, como accountability, lobbying e advocacy. Este processo tem tomado forma através do ciberespaço que se vai configurando como o espaço onde os actores sociais agem como produtores e receptores de mensagem e utilizam-no como ferramentas de disseminação da informação, se bem que ainda com poucos recursos. Nesta perspectiva, para Silveira (2009, p. 81-82) a internet revolucionou o campo da esfera pública, onde o cidadão comum, mesmo com poucos recursos tem a possibilidade de levar a sua mensagem para milhões de pessoas, e, de facto, "nunca cidadãos comuns produziram tanto conteúdo comunicacional, inclusive de carácter político, como ocorreu a partir do advento da comunicação em redes digitais distribuídas." Lemos (2009, p. 27) partilha da mesma visão, admitindo a hipótese de que actualmente o ciberespaço se configura como uma nova esfera pública, onde:

O "mundo da vida" amplia o capital social, recriando formas comunitárias, identitárias (público), ampliando a participação política. A função conversacional das mídias de função pós-massiva pode servir como factor privilegiado de resgate da coisa pública, embora não haja garantias. A participação, a colaboração e a conversação são as bases para uma acção política, mas não garantem a sua efectividade.
Actualmente no processo de mudanças estruturais que a democracia tem acompanhando, surgiram novas formas de participação na vida política nos países desenvolvidos e em vias de desenvolvimento. A classe política vem utilizando o ciberespaço para a promoção e divulgação de programas eleitorais, que possam ser socializados pelos cidadãos internautas, tanto residentes como nas diásporas. Um caso de sucesso foi a campanha eleitoral de Barack Obama, actual presidente dos Estados Unidos da América. Por outro lado, o ciberespaço tem sido utilizado para a promoção dos movimentos activistas um pouco por toda a parte, mesmo entre pessoas que nunca se encontraram nem se conhecem. Na verdade, através da mediação tecnológica, uma grande quantidade de pessoas, "dispersas geograficamente, e mesmo que nunca tenham antes interagido, pôde trabalhar num projecto comum de grandes dimensões e de relevante impacto social. Parte dessas pessoas pode ter como único interesse colaborar com a colectividade" (PRIMO, 2008, p. 58). Lévy (2007) um dos filósofos que melhor trabalhou a cibercultura considera que a esfera pública do século XXI caracteriza-se não só pela maior liberdade de expressão, mas acima de tudo por uma nova oportunidade de escolher as fontes de informação e uma nova liberdade de associação no seio de comunicação, grafos de relações pessoais ou conversas inovadoras que progridem em rede. Neste sentido, a própria comunicação digital e todos os seus instrumentos, possibilitam uma interconexão sem fronteira, e, de facto, é muita mais poderosa do que o próprio discurso ainda que bem elaborado.

Portanto, procura-se deste modo, abarcar a democracia em Cabo Verde com o objectivo de compreender a dinâmica da esfera pública a que também está intrinsecamente ligada a cultura cabo-verdiana e num contexto sócio-histórico e político onde a colonização e os regimes autoritários permaneceram durante quase cinco séculos.

\section{Cultura política e esfera pública no sistema político Cabo Verde: em busca de uma com- preensão}

\subsection{Da independência à Segunda República}

Como herança da colonização, a cultura política cabo-verdiana pode ser, ao que tudo indica, caracterizada até à abertura política como uma cultura de sujeição, onde a sociedade civil cabo-verdiana, pela sua formação sociocultural, se acomodou num sistema político e eco- 
nómico, de submissão e dependência e se reflecte naquilo que se pode descrever como o emblema identitário mais marcante na definição do ethos cultural crioulo que é a Morabeza (a ideia do homem cordial na sua convivência social) (PINA, 2013). Esta cultura, de uma certa forma, tem a sua repercussão na esfera pública cabo-verdiana, onde o Estado colonial proibia, através de diversos decretos-legislativos, algumas manifestações culturais dos quais se pressupunha possuírem características da cultura africana. A forma como se encontrava organizado o sistema social, político e económico no regime colonial, permitia que tanto a Igreja Católica como o Estado reprimissem quem transgredisse as normas cristãs, combatendo sistematicamente as "manifestações culturais africanas, desde a coladeira ao batuque, passando pela tabanca e por certas práticas de carácter animistas” (DUARTE, 2003, p. 94). E, de facto, toda a manifestação cultural de cariz africano era pura e simplesmente reprimida (LABAN, 1992). Neste âmbito, os intelectuais da época utilizavam a literatura como meio de interferirem subtilmente na esfera pública para discutir o quotidiano do povo cabo-verdiano, através de contos, crónicas e poesias. A esfera pública estava intrinsecamente ligada à imprensa que surgiu na década de quarenta do século XIX, e era denominada por mediadores de informações ou fazedores de opiniões, corroborada à teoria de two-step-flow of communication, ou teoria do fluxo da comunicação a dois níveis, proposta por Lazarsfeld; Berelson e Hazel (1944), em que a comunicação é determinada precisamente pela mediação que os líderes exercem entre os meios de comunicação e os outros indivíduos do grupo.

No período colonial em Cabo Verde os intelectuais eram denominados de elites culturais (a geração dos Nativistas e a geração dos Claridosos) que dominavam a esfera pública como líderes mediadores através de periódicos, jornais e revistas da época (1842 - 1950). Podem caracterizar-se estas gerações como líderes de opiniões (opinion leaders) que influenciavam de maneira informal atitudes individuais e padrões colectivos de comportamento, e estavam mais bem preparados e na posse de recursos que lhes permitiam a tarefa de mediação entre a antiga metrópole portuguesa e a população local (ANJOS, 2003). Estes líderes de opiniões eram os que se encontravam na posse do conhecimento e que até certo ponto, recorrendo à teoria de Foucault (2004), lhes dava o poder que era observado através do próprio discurso. Assim para Foucault existe uma relação íntima entre o conhecimento e o poder que este exerce dentro de um determinado grupo. E nesta lógica, este poder é exercido através do discurso e este discurso, por sua vez, é determinado pelo sujeito que obtém o saber ou o conhecimento.

A independência nacional (1975), apesar estabelecer a ruptura com o sistema colonial, seguiu igualmente as linhas do Estado colonial, principalmente no que se refere à organização do sistema administrativo. Esta continuidade teve a sua repercussão na esfera pública em que a elite da geração dos anos 50 (em que a maioria fez a sua formação superior na antiga metrópole portuguesa), fundadora do partido PAIGC/CV, passa a dominar a esfera pública e propagar a filosofia do partido único, num contexto onde os meios de comunicação de massa eram ainda escassos, com a primeira televisão a surgir só no ano de 1984, conhecida como a Televisão Experimental de Cabo Verde (TEVEC), e a Rádio Nacional de Cabo Verde em 1985, actualmente conhecidas pela fusão, como Rádio e Televisão de Cabo Verde (RTC).

Com um regime político de pendor socialista e paternalista, onde o Estado, sob a liderança do partido único controlava todos os sectores, principalmente o sector político e económico, contribuíu para a estruturação de uma esfera pública em que o diálogo e a opinião pública eram postas de lado, em detrimento de uma maior valorização dos ideais e filosofia do partido. A própria Constituição da República de 1980 era uma expressão do PAICV, das suas normas, directrizes, programas e estatuto e de outros documentos importantes do partido (FONSECA, 1990). Neste quadro, a colonização e o regime de partido único deixaram marcas visíveis na democracia e no advento da segunda República (1991). A dependência estrutural da sociedade civil cabo-verdiana e a colonização pelo Estado, bem como a sua apropriação e instrumentalização pelos partidos políticos "são tributários de atavismos históricos e duma cultura política cujos valores constitutivos corporizam ainda um habitus político autoritário" (COSTA 2013, p. 275). De uma cultura de sujeição passa-se para uma "cultura política de pendor particularista", que, segundo Pina (2013, p. 336), é entendida:

Como a tendência significativamente alargada de representações e atitudes impeditivos de uma convivência mais fortalecedora da esfera pública e da sociedade civil, incapazes de fomentar uma interacção mais regular e intima dos cidadãos com o funcionamento das estruturas políticas democráticas.

Neste contexto, o sentido de cidadania activa pro- 
tegida pela Constituição da República de Cabo Verde (1992) não se traduzia na prática social e política da sociedade civil cabo-verdiana, muito por culpa de incorporação de valores culturais e identitários nos quase cinco séculos de regimes autoritários. Costa (2013, p. 273) considera que a sociedade civil cabo-verdiana tem sido desde os primórdios da independência nacional até ao advento da segunda República, objecto de "açambarcamento", por parte dos partidos políticos e de demais interesses particularistas no que se refere a processos eleitorais e recrutamento político, "activando, consequentemente, lógicas clientelares, caciquistas e de patronagem política”. E mais, a fraca participação política da sociedade civil, e, por conseguinte, a fraca dinâmica da esfera pública estão intrinsecamente ligadas ao sistema político e económico cabo-verdiano. Num sistema político marcado por uma forte partidarização que acaba por influenciar o sistema económico, num pais com parcos recursos e em que um numero elevado de cidadãos depende do Estado no que se refere a própria criação de empregos.

\subsection{Dinâmica da esfera pública: o ciberespaço e as novas tendências}

No processo de crescente preocupação com a consolidação da democracia e particularmente das instituições politicas, tem-se verificado nos últimos anos uma nova dinâmica no que se refere à esfera pública em Cabo Verde. Uma dinâmica marcada por um novo modelo da esfera pública, mais inclusiva e que prima pelo respeito da opinião da sociedade civil cabo-verdiana de uma forma mais abrangente.

A emergência de movimentos cívicos um pouco por toda a parte, e particularmente no contexto dos sistemas políticos africanos, tem tido efeitos no contexto do sistema político cabo-verdiano. O ano de 2015, por exemplo, e como rescaldo do ano anterior, está sendo marcado por acontecimentos que, ao que tudo indica, apontam para uma nova abordagem da esfera pública em Cabo Verde. Fala-se essencialmente do Estatuto dos Titulares dos Cargos Políticos (ETCP), o que tem gerado um certo desconforto na classe política e uma maior afirmação da sociedade civil cabo-verdiana. A meu ver, com a emergência das TICs, foi graças ao ciberespaço no contexto cabo-verdiano, que surgiu o Movimento de Acção Cívica (MAC\#114), que reuniu cabo-verdianos residentes e nas diásporas, permitindo que estes se unissem por uma causa comum que de alguma forma é reconhecida e protegida pela Constituição da República. Hoje em dia o conceito que os cabo-verdianos têm sobre a esfera pública ou espaço público tem vindo a mudar significativamente. Varela (2015) refere que MAC\#114 surgiu depois de uma troca de ideias, na internet, entre um grupo de jovens da cidade da Praia com problemas e preocupações comuns, nomeadamente o desemprego e a falta de perspectivas em relação ao futuro. Aliás, Rony Moreira um dos seus fundadores, considera que era oportuno a criação e afirmação deste movimento num contexto em que não se verifica o hábito de manifestações cívicas, e onde as pessoas têm receio de dar a cara em relação a assuntos relacionados com a política e outros problemas sociais e económicos que assolam o arquipélago. Por outro lado, falta alguma organização entre aqueles que querem mostrar que estão insatisfeitos com o actual estado das coisas, particularmente com a organização do sistema político e económico. Para Rony Moreira, Cabo Verde está a ser controlado por uma pequena classe política que é detentora dos recursos financeiros, que absorve quase tudo e deixa poucas oportunidades para os outros. A ascensão social está relacionada com o poder que as pessoas têm, $\mathrm{e}$ a função pública em Cabo Verde é controlada pelos dois maiores partidos, PAICV e MpD, que defendem o seu status quo (VARELA, 2015). Perante este cenário, que teve uma repercussão considerável, e que só com um estudo mais detalhado é possível medir e avaliar, acredita-se que em Cabo Verde está a emergir uma nova esfera pública, que poderá ter como base essencial da sua sobrevivência e afirmação a internet, ou seja, o ciberespaço.

Após o debate em torno do Estatuto dos Titulares de Cargos Políticos, verificou-se uma queda acentuada da confiança da sociedade civil cabo-verdiana nas instituições políticas, corroborando o estudo da Afrosondagem (2015) que foi recentemente publicado. O estudo considera que os cabo-verdianos se mostram menos confiantes nas suas instituições, particularmente na Presidência da República, na Assembleia Nacional, no Primeiro-ministro, nos eleitos locais, nos partidos políticos na oposição (UCID e MpD), e no partido do Governo (PAICV). As previsões indicam que e a sociedade civil cabo-verdiana despertou para novos desafios no que se refere à própria afirmação de um novo espaço público que prima acima de tudo pelo debate e novas formas de liberdade de expressão. Sem um olhar romancista sobre os novos desafios da democracia cabo-verdiana, diria e com convicção, que é preciso ainda um trabalho de fundo, mas que a criação do 
MAC\#114 é um passo inigualável para a afirmação desta democracia, num contexto de grandes instigações políticas, sociais económicas e identitárias.

\section{Notas finais}

Para compreender actualmente a natureza e a afirmação da esfera pública é preciso também compreender a cultura política no contexto da democracia, entendendo-se cultura política como um conjunto de hábitos e costumes que estão intrinsecamente relacionados com a identidade de qualquer povo ou nação. De facto, a evolução da esfera pública é notável. Desde da antiguidade até aos dias de hoje verifica-se que a evolução da esfera pública está relacionada com os instrumentos de comunicação disponíveis e as TICs. Se por um lado, a própria democracia como um sistema político, que apresenta como um dos pilares fundamentais a liberdade de expressão, exige uma sociedade civil dinâmica e que tenha voz e vez, por outro, a própria estruturação da esfera pública como espaço de debate e de partilha de opiniões com a finalidade de se fazer ouvir perante um sistema político, precisa que todos os seus princípios sejam assegurados pelos sistemas políticos democráticos. Isto quer dizer que actualmente há uma intrínseca relação entre o funcionamento de uma esfera pública no verdadeiro sentido da palavra e um bom desempenho e estruturação do sistema político democrático.

No contexto cabo-verdiano, mostra-se necessária uma maior articulação entre a esfera pública e o sistema político democrático. E, se fizermos uma análise retrospectiva com atenção e um olhar crítico, é possível verificar uma evolução da esfera pública cabo-verdiana e ainda mais com o advento das TICs. Quero com isto dizer que, de facto, hoje podemos considerar que a esfera pública caminha para uma estruturação adequada e que corresponde às exigências do Estado de Direito Democrático cabo-verdiano. O desencadear dos movimentos cívicos, com particular destaque para o MAC\#114 permite considerar que existe hoje uma nova abordagem sobre a esfera pública cabo-verdiana, mas que, no entanto, é preciso fazer mais, num contexto de novas exigências politicas, económicas, sociais e culturais.

Concluindo, pressupõe-se que as instituições políticas cabo-verdianas necessitam de congregar esforços no sentido de atingir um desenvolvimento integrado com a sociedade civil, onde impera o bom senso e o diálogo, com o objectivo de cooperação, que implica o respeito mútuo e o benefício de todos. Portanto, deixamos em aberto outras possíveis leituras que poderão contribuir para se analisar e reflectir sobre o problema da democracia, cultura política e esfera pública em Cabo Verde.

\section{Referências}

AFROSONDAGEM. Perda generalizada de confiança nas instituições em Cabo Verde. Praia: Comunicado de Imprensa, 2015.

ALMOND, Gabriel; VERBA, Sidney. The civic culture: political attitudes and democracy in five nations. Princeton: Princeton University, 1963.

ANJOS, José Carlos. Elites intelectuais e a conformação da identidade nacional em Cabo Verde. Estudos AfroAsiáticos, Rio de Janeiro, ano 25, n. 3, p. 579-596, 2003.

ARENDT, Hannah. A condição humana. Rio de Janeiro: Forense Universitária, 2007.

AVRITZER, Leonardo. A moralidade da democracia. São Paulo: Perspectiva, 1996.

BARATA, Alexandre Mansur. Maçonaria, sociabilidade ilustrada e independência do Brasil (1790-1822). São Paulo: UFJF, 2006.

BOBBIO, Norberto. Dicionário de política. Brasília: UnB, 2000.

BOURDIEU, Pierre. A opinião pública não existe. In: THIOLLENTE, Michel (Org.). Crítica metodológica, investigação social e enquete operária. São Paulo: Polis, 1980. p. 137-151.

COSTA, Suzano. Sociedade civil, estado e qualidade da democracia em Cabo Verde: entre a letargia cívica e a omnipresença do Leviatã. In: SARMENTO, Cristina; COSTA, Suzano (Org.). Entre África e a Europa: nação, estado e democracia em Cabo Verde. Coimbra: Almedina, 2013. p. 273-329.

DUARTE, Dulce Almada. Bilinguismo ou diglossia? Praia: Spleen, 2003.

FRANÇA, Arnaldo. O nascimento e o reconhecimento de uma literatura em prosa. In: VEIGA, Manuel (Coord.). Cabo Verde: insularidade e literatura. Paris: Karthala, 1998. p. $44-48$.

FERREIRA, Manuel. A aventura crioula. Lisboa: Plátano, 1973.

FONSECA, Jorge Carlos. O sistema de governo na Constituição cabo-verdiana. Lisboa: AAFDL, 1990. 
FOUCAULT, Michel. A ordem do discurso. São Paulo: Loyola, 2004.

HABERMAS, Jürgen. Mudança estrutural da esfera pública. Rio de Janeiro: Tempo Brasileiro, 2003.

HABERMAS, Jürgen. Direito e democracia: entre facticidade e validade. Rio de Janeiro: Tempo Brasileiro, 1997.

LABAN, Michel. Cabo Verde: encontro com escritores. Porto: Fundação Engenheiro António de Almeida, 1992.

LAFER, Celso. Hannah Arendt: pensamento, persuasão e poder. São Paulo: Paz e Terra, 2003.

LAZARSFELD, Paul; BERELSON, Bernard; GAUDET, Hazel. The people's choice. New York: Columbia University, 1944.

LEMOS, André. Nova esfera conversacional. In: MARQUES, Ângela et al. (Org.). Esfera pública, redes e jornalismo. Rio de Janeiro: E-Papers, 2009. p. 9-30.

LEVY, Pierre. Cibercultura. São Paulo: 34, 2007.

NORBERTO, Bobbio. Liberalismo e democracia. São Paulo: Brasiliense, 2000.

OLIVEIRA, João Nobre de. A imprensa cabo-verdiana 1820-1975. Macau: Fundação Macau, 1998.

PEREIRA, Marcus Abílio; CARVALHO, Ernani. Boaventura de Sousa Santos: por uma nova gramática do político e do social. Revista Lua Nova, São Paulo, n. 73, p. 45-58, 2008.
PINA, Leão Jesus de. Tendências de cultura política, democratização e esfera publica em Cabo Verde. In: SARMENTO, Cristina; COSTA, Suzano (Org.). Entre África e a Europa: nação, estado e democracia em Cabo Verde. Coimbra: Almedina, 2013. p. 331-354.

PRIMO, Alex. Fases do desenvolvimento tecnológico e suas implicações nas formas de ser, conhecer, comunicar e produzir em sociedade. In: PRETTO, Nelson; AMADEU, Sérgio (Org.). Além das redes de colaboração: internet, diversidade cultural e tecnologias do poder. Salvador: EDUFBA, 2008. p. 51-68.

RAWLS, John. O liberalismo político. Lisboa: Presença, 1997.

SILVEIRA, Sérgio Amadeu da. Esfera pública interconetada, blogosfera e redes sociais. In: MARQUES, Ângela et al. (Org.). Esfera pública, redes e jornalismo. Rio de Janeiro: E-Papers, 2009. p. 70-89.

TAYLOR, Charles. A esfera pública. Covilhã: Universidade da Beira Interior, 2010.

VERELA, Aquilino. Estatuto dos políticos: Cabo Verde à beira da revolução. $A$ voz: Semanário Independente de Cabo Verde, ano 1, n. 11, p. 2-4, 2015.

VON MISES, Ludwig. Liberalismo segundo a tradição clássica. São Paulo: Instituto Ludwig von Mises, 2010. 